Research Paper

\title{
Identification of evolutionarily conserved DNA damage response genes that alter sensitivity to cisplatin
}

\author{
Anna V. Gaponova ${ }^{1,2}$, Alexander Y. Deneka ${ }^{1,2}$, Tim N. Beck ${ }^{1,3}$, Hanqing Liu ${ }^{1,4}$, Gregory \\ Andrianov ${ }^{2}$, Anna S. Nikonova ${ }^{1}$, Emmanuelle Nicolas ${ }^{1}$, Margret B. Einarson ${ }^{1}$, Erica \\ A. Golemis ${ }^{1}$, Ilya G. Serebriiskii, ${ }^{1,2}$ \\ ${ }^{1}$ Molecular Therapeutics, Fox Chase Cancer Center, Philadelphia, PA 19111, USA \\ ${ }^{2}$ Department of Biochemistry and Biotechnology, Kazan Federal University, Kazan 420008, Russian Federation \\ ${ }^{3}$ Department of Biochemistry \& Molecular Biology, Program in Molecular and Cell Biology and Genetics, Drexel University \\ College of Medicine, Philadelphia, PA 19129, USA \\ ${ }^{4}$ Department of Pharmaceutics, Jiangsu University, School of Pharmacy, Jingkou District Zhenjiang, Jiangsu 212013, China \\ Correspondence to: llya G. Serebriiskii, email: llya.Serebriiskii@fccc.edu \\ Erica A. Golemis, email: Erica.Golemis@fccc.edu
}

Keywords: platinating agents, resistance, DNA damage response, head and neck cancer

Received: September 08, 2016

Accepted: October 27, 2016

Published: November 15, 2016

\section{ABSTRACT}

Ovarian, head and neck, and other cancers are commonly treated with cisplatin and other DNA damaging cytotoxic agents. Altered DNA damage response (DDR) contributes to resistance of these tumors to chemotherapies, some targeted therapies, and radiation. DDR involves multiple protein complexes and signaling pathways, some of which are evolutionarily ancient and involve protein orthologs conserved from yeast to humans. To identify new regulators of cisplatin-resistance in human tumors, we integrated high throughput and curated datasets describing yeast genes that regulate sensitivity to cisplatin and/or ionizing radiation. Next, we clustered highly validated genes based on chemogenomic profiling, and then mapped orthologs of these genes in expanded genomic networks for multiple metazoans, including humans. This approach identified an enriched candidate set of genes involved in the regulation of resistance to radiation and/or cisplatin in humans. Direct functional assessment of selected candidate genes using RNA interference confirmed their activity in influencing cisplatin resistance, degree of $\mathrm{YH} 2 \mathrm{AX}$ focus formation and ATR phosphorylation, in ovarian and head and neck cancer cell lines, suggesting impaired DDR signaling as the driving mechanism. This work enlarges the set of genes that may contribute to chemotherapy resistance and provides a new contextual resource for interpreting next generation sequencing (NGS) genomic profiling of tumors.

\section{INTRODUCTION}

Platinating compounds including cisplatin, oxaliplatin, and carboplatin are mainstays of therapy for many cancers, including among others head and neck, ovarian, bladder, colorectal, and lung tumors [1]. These agents function primarily by modifying DNA, forming intrastrand crosslinks and other DNA lesions that, if unrepaired, lead to activation of cell death pathways in replicating cells; in additional secondary functions, interaction of platins with cytoplasmic targets increases oxidative stress and thereby provides an independent trigger of cell death [2]. When platins are applied at lower concentrations, cells undergo a transient arrest in the $\mathrm{S}$ and $\mathrm{G} 2$ phases of the cell cycle. This pause allows proteins in the nucleotide excision repair (NER) and homologous recombination (HR) pathways to eliminate platinum adducts and restore DNA integrity, preventing acquisition of deleterious mutations and abnormal mitoses. Beyond a lethal dosage threshold, activation of the ATM, ATR, and CHEK1 kinases initiates a signaling cascade that culminates in mitochondrial permeabilization and apoptosis [3-5].

Although platinum agents provide significant clinical benefit, tumors often develop resistance. Numerous mechanisms of resistance to platins have been 
described [6]. These include changes in the expression and activity of membrane transporters and the endocytic machinery, which reduce the intracellular concentration of platinating compounds; changes in heat shock proteins and other mediators of cellular stress response; changes in chromatin and DNA conformations that result in differential accessibility of the DNA target; transcription of genes that promote survival signaling; and changes in the DNA damage response (DDR) pathways that repair platinum and radiation induced DNA lesions [7]. These last mechanisms are of particular clinical interest, because they are associated with development of crossresistance to multiple DNA damaging therapies, and therefore broadly reduce therapeutic options [8]. For example, overexpression of nucleotide excision repair (NER) proteins such as ERCC1 [9], proteins involved in translesion synthesis (also known as replicative bypass), including the polymerases POLH or REV3L [10], and proteins that mediate homologous recombination (HR) such as BRCA1 and BRCA2 [11-13], have all been associated with cisplatin resistance.

As genomic and proteomic data have become available in the past decade, it has become increasingly apparent that the number of proteins contributing to DDR processes is much greater than previously thought $[14,15]$. Indeed a growing number of components involved in DNA repair systems have been defined. Based on analysis of these components, it has become clear that for many vital cellular processes, changes in gene expression or function that affect phenotypes of interest can be dispersed throughout extended signaling networks [16-18]. In this context, even as genomic profiling has become more standard in the clinic [19, 20], it remains a challenge to identify functionally essential components of the DDR response apparatus relevant to clinical resistance to cisplatin and other DNA damaging therapies.

We hypothesized that DDR genes are likely evolutionarily conserved, considering that maintenance of DNA integrity is critical for survival, which suggested a new approach to identify functionally important regulators of cisplatin resistance in human tumors. Based on this hypothesis, we analyzed data from the Saccharomyces cerevisiae genome database (SGD) and a large number of other functional screens for genes conferring of cisplatin resistance in lower organisms. To enrich the resulting dataset for genes relevant to DDR, we then integrated this information with additional data describing genes functionally defined as important for different classes of DDR, including data for $\gamma$-ray-, X-ray-, and UV-induced damage. Lastly, we directly tested human orthologs of genes identified in this manner for cellular responses to cisplatin in human cancer models, resulting in the identification of novel resistance mediators.

\section{RESULTS}

\section{Integration of function-based datasets to define genes that regulate resistance to DNA damage in S. cerevisiae}

To test the hypothesis that DNA damage response genes in lower eukaryotes could identify human genes regulating cisplatin resistance, we extracted a first dataset from the SGD [21] based on phenotypebased query to identify genes where loss-of-function mutations altered sensitivity to $\gamma$-ray, X-ray, or UV irradiation and/or cisplatin treatment (832 and 126 genes, respectively; Figure 1A, 1B). This captured data from 105 low throughput screening (LTS) studies, typically characterizing 1-10 genes in detail. A second dataset was manually extracted from 12 published high throughput screening (HTS; defined as screening $>15 \%$ of the genome) genetic studies [22-33], which was integrated with additional information from the SGD. For these datasets, results were reported in binary terms (sensitizing or not sensitizing).

Integrated analysis of genes designated as contributing to UV- and radiation-resistance from datasets 1 and 2 (designated LTS and HTS, subsequently) indicated that $29 \%$ and $21 \%$ of genes in these sets, respectively, were identified in two or more studies (Figure 1B). Genes identified in LTS were more likely to be repeatedly identified and demonstrated statistically significant enrichment of gene ontology (GO) terms associated with DNA repair, cell cycle and chromosomal organization (Figure 1C). Candidates identified by a single HTS $(\mathrm{HTS}=1)$ showed little or no enrichment in these gene ontology (GO) terms; however, a group of 164 candidates nominated by at least 2 studies (HTS $\geq 2$ ) demonstrated enrichment in gene ontology terms similar to the LTS subset (Figure 1C). Combined, the LTS and HTS $\geq 2$ groups identified 263 genes involved in $\gamma$-ray-, X-ray-, and UVresistance (Supplementary Table 1). A similar analysis for genes specifically implicated in cisplatin-resistance yielded a total of 126 genes, with data from both LTS and HTS. The combined LTS/HTS dataset was highly enriched for gene ontology annotations associated with DNA repair, cell cycle and chromosomal organization (Figure 1C, Supplementary Table 2). This is consistent with the idea that the selection criteria employed were appropriate for identification of genes with a plausible, direct connection to regulation of cisplatin sensitivity.

To augment this analysis, an additional dataset was collected from a group of three functional chemogenomics screening studies (CGS) (http://fitdb.stanford.edu; [34, 35]). In these large studies, a genome-wide panel of yeast strains, each mutated in a single gene, was challenged with different drugs over broad concentration ranges, providing continuous measurements to characterize the relative importance of 
each of the mutated genes in terms of resistance. Genes identified in the binary screens (datasets 1 and 2) were more frequently found among genes with greater importance for drug resistance (higher "fitscores") in the chemogenomics screens performed with cisplatin (Supplementary Figure 1). Using data extraction cutoffs selected to reduce the fraction of false positives (see Supplementary Materials and Methods), we considered genes identified in two or more chemogenomics studies as most important for cisplatin resistance. This work nominated 214 genes associated with cisplatin resistance and with high fitscores in $\geq 2$ two chemogenomics studies (including 55 shared between datasets from all three chemogenomics studies) (Figure 1D, dark blue highlighted area). The resulting combined dataset was highly enriched in Gene Ontology (GO) annotations associated with DNA repair, cell cycle, chromosomal organization, and other relevant functions. 54/214 of the identified genes were independently identified in the binary studies as contributing to cisplatin resistance. Merging candidate cisplatin resistance datasets resulted in a list of 286 genes (Figure 1D, Supplementary Table 2).

\section{Integration based on chemogenomic profile}

Proteins that collaborate to execute specific biological processes often show a common pattern of essentiality across multiple growth conditions [36]. As an orthogonal approach to gain insight into cisplatin resistance and DDR functions, we sought to identify genes with overall phenotypic profiles similar to those of well-established, functionally relevant resistance genes. To this end, we analyzed the distribution of the 286 selected candidate genes across co-fitness gene clusters that were based on a comprehensive chemogenomic study, which reported the overall profiles of growth of 4,769 homozygous yeast deletion strains [37] in 418 culture conditions, including treatment with FDA-approved drugs and other bioactives.

From this analysis, we identified 11 clusters that were enriched $(p \leq 0.001)$ for the $\mathrm{LTS} / \mathrm{HTS} / \mathrm{CGS} \geq 2$ radiation and/or cisplatin resistance-modulating genes (Figure 2A, 2B, Table 1; extended data in Supplementary Table 3), including two clusters (CL10 and CL11) enriched for cisplatin resistance only. In addition to enrichment for DDR-related gene ontology annotations (CL2, 5-7), some clusters were also enriched in related functions such as chromatin assembly and chromosome organization (CL2, 5-7, 9, 11) (Figure 2B, Table 2). Contrasting the two clusters with the greatest level of enrichment for DDR-related functions (CL5 and CL7), the genes in CL5 provided highly significant resistance not only to multiple platinum compounds, but also to many other classes of DNA damaging agents, including cantharidin, bleomycin, chlorambucil, and others, while those in CL7 were more restricted in activity (Supplementary Table 4).
In contrast, for some clusters (e.g., CL3 and 4), the greatest GO terms enrichment reflected processes related to overall cellular robustness (e.g., mitochondrial function or vesicle-mediated transport; Figure 2B); not surprisingly, in chemogenomics profiling these clusters also show overabundance of genes responding to other cellular stresses such as heat sensitivity. Among genes originally nominated from cisplatin resistance sets, fewer were annotated for DDR-related processes compared to genes identified based on resistance to UV/radiation, potentially reflecting the greater diversity of cisplatin resistance mechanisms.

Interestingly, some of the clusters contained more of the genes initially defined as lower confidence, originating from the UV_rad HTS $=1$ set or only had a single high score for cisplatin sensitization from a single chemogenomics screen, a finding unlikely to have occured by chance $(\mathrm{p}<0.05$; Table 1 , Supplementary Tables 1, 3). Although many of the $\mathrm{HTS}=1$ candidates most likely represented false positive hits in functional screening assays, the additional evidence from co-fitness profiling linked some of these genes to the high value set of resistance regulators. Thus, these data suggested an additional 126 yeast genes that may be functionally linked to resistance to DNA damaging agents, albeit with a weaker phenotype (Supplementary Tables 2, 3).

\section{$\mathrm{UV}$ and radiation resistance genes in flies and worms}

To provide additional insight, we analyzed resources in FlyBase [38], FlyMine [39], Wormbase [40], and Pubmed to identify genes linked to radiation or cisplatin resistance based on resistance screens performed in the fruitfly D. melanogaster (69 genes) or the roundworm C. elegans (34 genes) (Supplementary Tables 5-6 and Supplementary Figure 2). Of these, 26/65 genes in $D$. melanogaster and 23/34 in C. elegans have orthologs in yeast, of which $14 / 26$ and $15 / 23$, respectively, were also identified in yeast as modulating $\mathrm{UV} /$ radiation sensitivity (Supplementary Tables 5-6). The small number of genes thus identified most likely reflects the relatively limited number of screening studies in these organisms specifically focused on DNA damage resistance. Conversely, of the genes shown to increase UV and/or radiation sensitivity in $S$. cerevisiae, 169 were evolutionarily maintained (based on sequence conservation) in D. melanogaster and 162 in $C$. elegans, with the majority of the genes (156) conserved in both. However, fewer than $50 \%$ of these conserved genes were annotated as relevant to DDR processes (79/169 fly genes and 75/162 worm genes). This lack of annotation mostly likely reflects the much more systematic functional screening efforts in S. cerevisiae, although it may also reflect altered activity of these genes in metazoans. 


\section{Conservation of $U V$, radiation, and cisplatin- resistance genes in humans}

We next identified the human orthologs of genes annotated as relevant to UV, radiation, or cisplatin resistance in yeast (Figure 2C). Because of gene duplication and other events, in some cases individual genes in yeast are represented by paralogous gene families in humans, gene-ortholog assignment was inexact; however, approximately $45 \%$ of yeast genes linkage to UV, radiation, or cisplatin resistance with high confidence, had definable human orthologs or paralog sets. The fraction of S. cerevisiae genes identified through primary resistance to $\mathrm{UV} /$ radiation or cisplatin had similar frequencies for human orthologs. Side-by-side juxtaposition of genes in yeast CL5 (Figure 3A, left) and CL7 (Figure $3 \mathrm{~B}$, left) with human orthologs (Figure 3A, 3B, right) emphasizes that most of the genes thus identified in yeast are conserved in humans. Among the human orthologs, $20 \%$ are functionally annotated in Ensemble (release 84, 2016) as having DDR-related functions, particularly for orthologs of yeast genes identified for roles in regulating UV or radiation responses (Supplementary Figure 2). These included highly validated proteins with homologs such as ERCC1, ERCC4, XRCC3, and RAD54. Figure $3 \mathrm{C}$ illustrates a subset of genes in the nucleotide excision repair (NER) complex, enriched in CL7. Overall, this analysis based on yeast, fly and worm genes implicated 684 human genes as potentially involved in resistance to UV, radiation, or cisplatin (Supplementary Table 7).

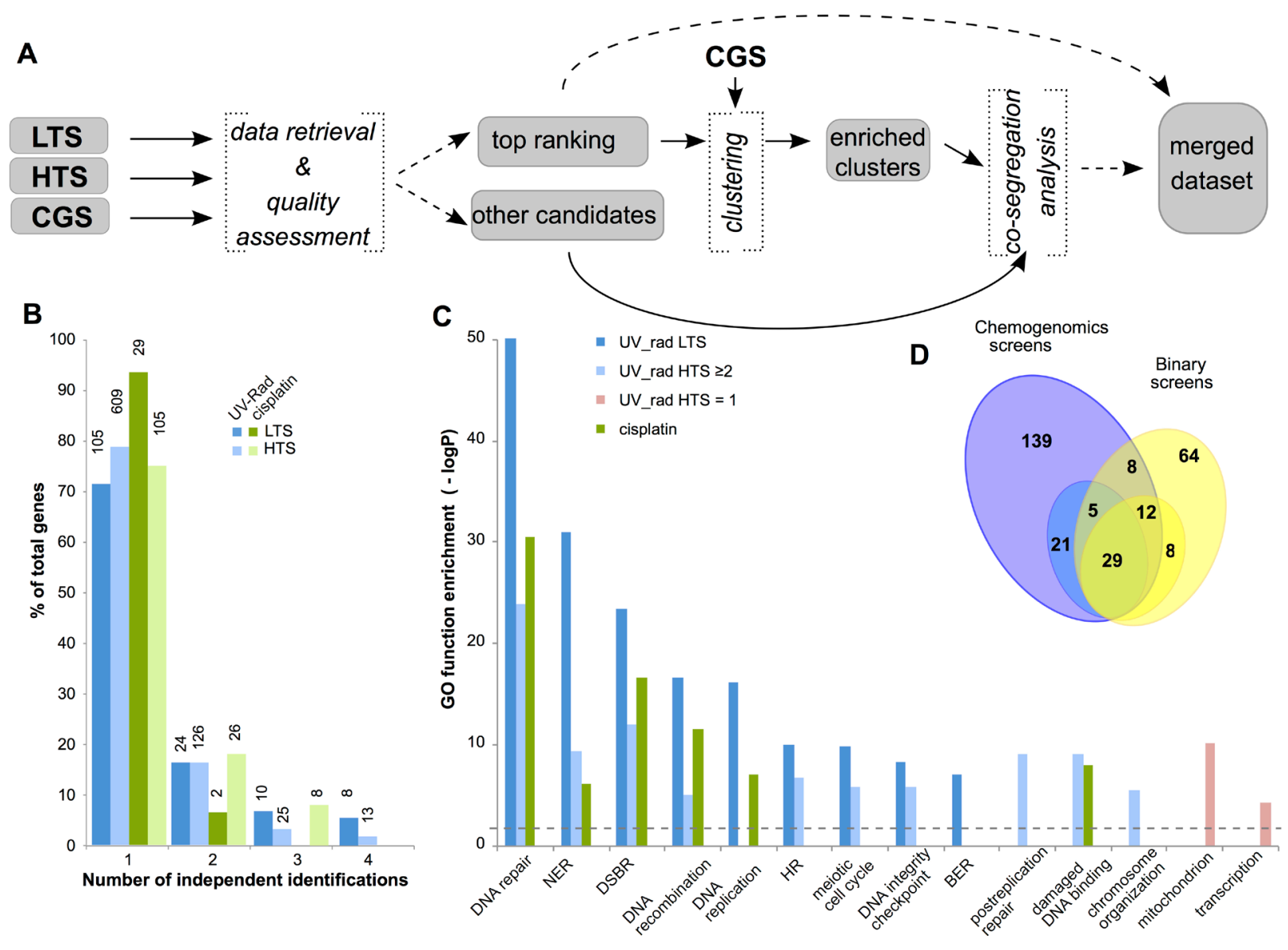

Figure 1: Identification of yeast genes mediating response to UV, X-ray radiation, or cisplatin. A. Workflow for identification of yeast genes modulating sensitivity to UV, ionizing radiation, and cisplatin treatment. LTS, low throughput screen; HTS, high throughput screen; CGS, chemogenomic screen. B. Classification of candidate genes based on the number of independent studies that identified each gene as contributory to resistance to UV or radiation (UV_rad) or to cisplatin, as well as by type of supporting study (LTS and HTS). Y-axis indicates percent of genes for each class, while the absolute number of supporting studies is shown on the top of each bar. C. Enrichment in GO terms for specific subsets of candidate genes. NER, nucleotide excision repair; DSBR, double strand break repair; HR, homologous recombination; BER, base excision repair. Dashed line indicates the threshold for the statistical significance. D. Overlap between cisplatin resistance gene sets identified in binary LTS/HTS (yellow) and chemogenomic (blue) screens: numbers represent individual genes. Darker colors indicate genes supported by $\geq 2$ binary screens, or by 3 independent chemogenomic studies; lighter colors indicate genes supported by 1 binary screen, or by 2 of 3 chemogenomic studies. 
A

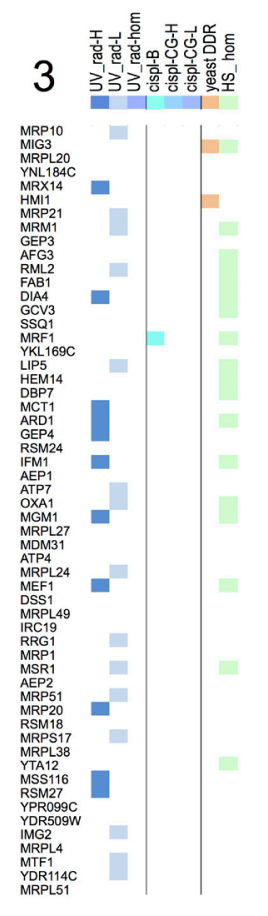

B
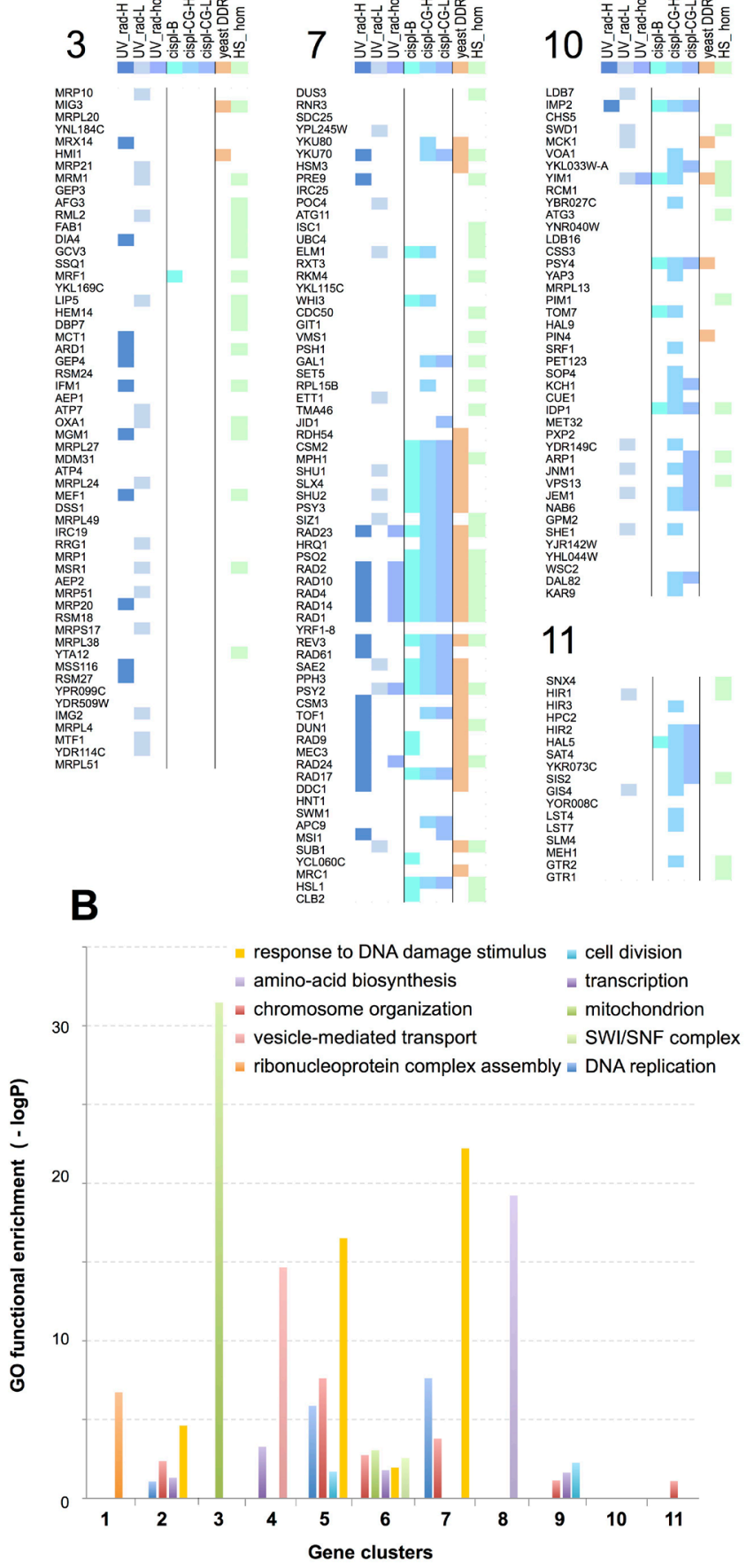

11

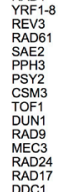

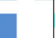

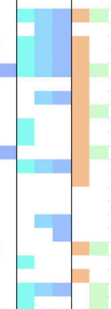

C

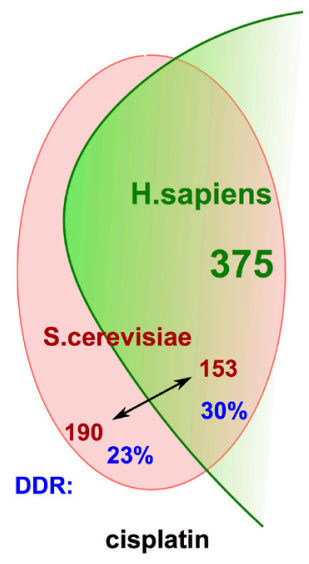

Figure 2: Examples of functional clusters of genes regulating response to UV, X-ray radiation, or cisplatin. A. Graphical representation of composition and selected properties of clusters (CL) enriched in UV_rad sensitivity-modulating genes (CL 3), in cisplatin sensitivity-modulating genes (CL 10 and 11), or in both (CL 7). Key indicates genes identified as UV rad HTS $\geq 2$ and/or UV rad LTS (UV_rad-H); or as inducing cisplatin resistance from binary (cispl-B), or chemogenomics (cispl CG-H) with high statistical significance (see text for details). Genes initially defined as lower confidence because of identification from the UV_rad HTS=1 set alone, or only by a single high score for cisplatin sensitization from a single chemogenomics screen, but significantly enriched $(p<0.05)$ within clusters, are denoted as "UV_rad-L" and "cispl-CG-L", respectively. "Yeast DDR" indicates genes annotated as involved in response to DNA damage; "UV_rad-hom" indicates functional orthologs in fly and/or worm; "HS_hom", genes have unambiguous orthologs in H. sapiens. See Supplementary Table 3 for detailed information on all identified clusters. B. Enrichment in Gene Ontology (GO) functions for the identified clusters. C. Overall evolutionary conservation of $S$. cerevisiae cisplatin resistance genes in $H$. sapiens. Numbers shown in red font represent individual yeast genes, while green font is used for the number of human genes orthologous to the yeast counterpart. The fraction of yeast genes annotated as involved in DDR is shown in blue. 
Table 1: Enrichment of candidate gene sets in clusters

\begin{tabular}{|c|c|c|c|c|c|}
\hline Cluster number & $\begin{array}{c}\text { UV_rad LTS/ } \\
\text { HTS } \geq 2\end{array}$ & UV_rad HTS=1 & $\begin{array}{c}\text { cisplatin binary } \\
\text { studies }\end{array}$ & $\begin{array}{l}\text { cisplatin chemogenomics } \\
\text { studies }\end{array}$ & Human DDR \\
\hline 1 & $* * * *$ & $* * * *$ & $*$ & $-/ * *$ & \\
\hline 2 & $* * *$ & $* *$ & & $-/ * * * *$ & \\
\hline 3 & $* * * *$ & $* * * *$ & & & \\
\hline 4 & $* * * *$ & $* * * *$ & $* * * *$ & $-/ * * * *$ & \\
\hline 5 & $* * * *$ & $* * * *$ & $* * * *$ & $* * * * / * * * *$ & $* * * *$ \\
\hline 6 & $* *$ & $* * * *$ & & $-/ * * *$ & \\
\hline 7 & $* * * *$ & $*$ & $* * * *$ & $* * * * / * * * *$ & $* * * *$ \\
\hline 8 & $* *$ & & $* *$ & $* / * * *$ & \\
\hline 9 & $* * * *$ & $* * *$ & & & \\
\hline 10 & & & & $* / * * * *$ & \\
\hline 11 & & & & $* * / * * * *$ & \\
\hline
\end{tabular}

$\mathrm{P}$ values indicate the enrichment of each indicated cluster with genes from the indicated data sets, and also likelihood that clusters have human homologues with DDR annotation. *, $\mathrm{p}<0.05 ; * *, \mathrm{p}<0.01 ; * * *, \mathrm{p}<0.001 ; * * * *, \mathrm{p}<0.0001$; $* * * *$ (red font), $\mathrm{p}<0.00001$.

\section{RNAi assessment of roles for candidate genes involved in cisplatin resistance in human cancer models}

We sampled genes identified from conservation with functionally defined yeast genes, choosing 5 from clusters and one not (UBE2V2), for direct evaluation for roles in cisplatin resistance in human cells. Head and neck cancers (HNCs), and epithelial ovarian cancers (EOCs) are commonly treated with cisplatin and other platinum-based compounds [8, 41]. We therefore used the cisplatin-resistant serous EOC cell line OVCAR-8, and two HNC cell lines, SCC61 and SCC25, as models. For each cell line, we used two pooled small interfering RNAs (siRNAs) to deplete a positive control gene (REV3L, previously defined as contributing to cisplatin resistance [10]), a negative control scrambled siRNA (siGL2), or genes identified in our analysis (Figure 4, Supplementary Table 8) but never previously defined as regulating cisplatin sensitivity in humans. 24 hours after transfection, cells were treated with vehicle, or an IC20IC30 concentration of cisplatin previously established for each cell line (Figure 4A). As all of the genes were evolutionarily conserved and often associated with biologically essential functions, we first established the intrinsic effect of each siRNA pool on fundamental cell viability using CellTiterBlue (Figure 4B). At 72 hours after vehicle treatment, three genes (POLR2I, RAD54L, and WDHD1) significantly reduced viability (by $30-60 \%$ ) in 2 of the 3 cell lines tested, while 3 genes (UBE2V2, DSCC1, and CSNK2B) had little or no effect on viability.
We then gauged the ability of each siRNA pool to sensitize cells to cisplatin (Figure 4C), 72 hours after drug treatment. Only a limited sensitization effect was observed in the cisplatin-resistant OVCAR-8 line with depletion of UBE2V2, DSCC1, and CSNK2B. In contrast, depletion of UBE2V2, DSCC1, and CSNK2B had a marked sensitization effect in SCC61 and SCC25 cells. In addition, depletion of POLR2I, RAD54L, and WDHD1 each had a sensitizing effect in these cell lines, independent of their fundamental role in viability. As a control for specificity, we used qRT-PCR, confirming that individual siRNAs efficiently depleted their target mRNAs (Supplementary Figure 3). We also asked if the sensitization phenotypes observed were specific to treatment of cells with cisplatin, or whether depletion of the selected genes sensitized cells to additional drugs that caused DNA damage. 5-fluorouracil (5-FU) causes DNA damage by inducing unbalanced replication due to depletion of thymine pools, and olaparib causes DNA damage by inhibiting poly-ADP ribose polymerase (PARP1) [42, 43]. We found the pattern of sensitization to these drugs closely paralleled that seen with cisplatin; notably, depletion of WDHD1 had a very striking effect on sensitization to the PARP1 inhibitor olaparib (Figure 4D).

\section{Cisplatin sensitivity candidate genes influence magnitude and duration of $\gamma \mathrm{H} 2 \mathrm{AX}$ foci formation induced by cisplatin}

Cisplatin triggers a DNA damage response characterized by the formation of phosphorylated histone 
Table 2: Enrichment of clusters for Gene Ontology (GO) functions related to DNA damage, cell cycle, and chromosomal organization

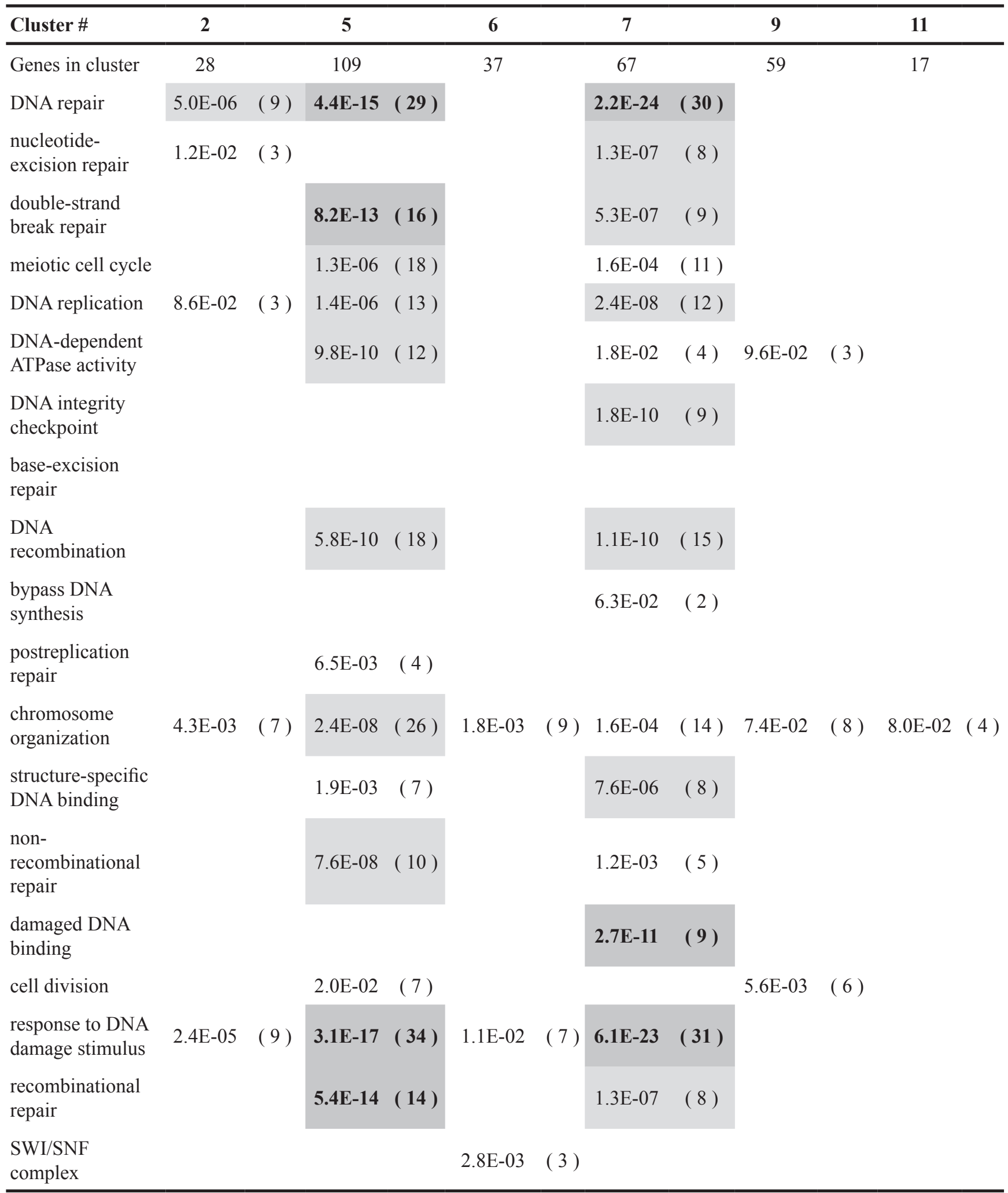

$\mathrm{P}$ values for the indicated GO function enrichment are shown (with the corresponding number of genes in parentheses). Only clusters with significant $(\mathrm{p}<0.05)$ values for the indicated categories are given. Color codes for $\mathrm{p}$-value: light gray,

$<1.0 \mathrm{E}-5$; dark grey, $<1.0 \mathrm{E}-10$. 
$\mathrm{H} 2 \mathrm{AX}(\gamma \mathrm{H} 2 \mathrm{AX})$-positive foci at the site of DNA damage $[44,45]$, dependent on the action of ATR and associated with the induction of downstream CHEK1 or CHEK2 kinases [46]. We investigated whether the candidate gene set impaired appearance of $\gamma \mathrm{H} 2 \mathrm{AX}$ foci following cisplatin treatment (Figure 5A-5C). After depleting candidate or control genes for 24 hours, we treated SCC61, SCC25, or OVCAR-8 cells for 18 hours with vehicle or 16 $\mu \mathrm{M}$ of cisplatin, and then assessed the degree of $\gamma \mathrm{H} 2 \mathrm{AX}$ foci formation. A CHEK1-depletion control showed elevated foci formation in vehicle-treated cells, reflecting induction of a DNA damage response, in agreement with previous reports [47]. In contrast, depletion of the sensitization candidate genes either indicated no effect, or reduction in basal levels of DNA damage foci in vehicletreated cells (Figure 5).

We then examined $\gamma \mathrm{H} 2 \mathrm{AX}$ foci formation induced by cisplatin. In this context, the CHEK1-control depleted cells had fewer foci than GL2/vehicle-treated cells, reflecting the uncoupling of the DNA damage response signaling system. Strikingly, all 6 of the genes of interest significantly reduced cisplatin-induction of $\gamma \mathrm{H} 2 \mathrm{AX}$ foci in at least 2 of 3 cell models. Some of the most striking effects were observed in the cisplatin-resistant OVCAR-8 cell model, with depletion of UBE2V2 and WDHD1 almost eliminating cisplatin response, in spite of having no effect on basal levels. These results suggested potential defects in DNA damage response signaling associated with depletion of the genes of interest. Supporting this interpretation, Western analysis of control or genedepleted cells treated with vehicle or cisplatin for 18 hours showed distinct patterns of phosphorylated (active) ATR (Figure 5D). Referenced to vehicle-treated, GL2-depleted cells, depletion of WDHD1, RAD54L, and CSNK2B elevated basal activation of ATR; in contrast, in cells treated with cisplatin, the induction of phospho-ATR was significantly reduced following depletion of WDHD1, DSCC1, CSNK2B, POLR2I, and RAD54L.

Finally, the Cancer Genome Atlas (TCGA) reports genomic and transcriptomic data on $530 \mathrm{HNCs}$ (including 488 human papillomavirus negative (HPV-) HNCs) [4850] and 540 EOCs [51], with additional information available via cBioPortal [52]. Analyzing this data, we found gene amplification (Figure 6A) and overexpression (Figure 6B) of WDHD1, RAD54L, CSNK2B, UBE2V2, POLR2I and DSCC1 in a significant subset of these tumors, suggesting variation in the expression of these genes might contribute to innate resistance to cisplatin, radiation therapy, and other DNA damaging agents.

\section{DISCUSSION}

In summary, this study systematically mined large scale datasets to generate a comprehensive set of $S$. cerevisiae genes that functionally influence resistance to cisplatin, UV, and radiation; we then used clustering and analysis of evolutionary conservation to map this set of genes to human orthologs. The ultimate goal of this work was to evaluate whether functional analysis of genes in yeast and other lower eukaryotes could help identify human genes important for the resistance to DNA-damaging drugs commonly used to treat cancer, particularly cisplatin. The generated datasets (Supplementary Tables 1-2,7) represent a novel and useful resource for the field.

By integrating multiple datasets linked to DDR responses, we identified a group of genes that affect these processes and have been highly validated in lower eukaryotes, with a subset of these genes segregating into clusters with specific chemogenomic profiles. Human orthologs of genes in these clusters include many already highly validated for roles in DNA repair, such as ERCC1/4/5, CHEK1/2, WRN, BLM, and others. The identified clusters also include genes annotated for DNA repair in yeast but not in humans, and genes such as PIAS1, human ortholog of SIZ1, which may influence activity of DNA repair proteins through a SUMOylation mechanism [53]; BRSK1, ortholog of HSL1, a little studied kinase typically considered a regulator of spindle-formation and centrosomes, although noted in one older study as potentially involved in an alternative UV checkpoint [54]; and the genes POLR2I, WDHD1, CSNK2B and DSCC1 (orthologs of RPB9, CTF4, CKB2 and DCC1), investigated functionally in human cells here. Interestingly, these clusters also contained a number of genes with similar chemogenomic phenotypes that were not annotated for roles in DDR in humans or yeast: these gene pairs, such as ISC1/SMPD2, RKM4/SETD6, and others, are candidates for future evaluation.

Subsequent direct evaluation of a set of human orthologs of genes selected to contain some from within clusters, and some not part of clusters, indicated that a number of them influenced resistance to multiple DNA damaging agents. Of the specific genes we sampled, some have known roles as components of specific DNA repair machineries. For example, UBE2V2 is a variant ubiquitin-conjugating E2 enzyme that is orthologous to the yeast MMS2 gene, implicated in HR and translesion synthesis, that has been shown to promote UV resistance in human cells, with overexpression linked to poor prognosis in some cancer types [55]. RAD54L is a DEAD-like helicase/translocase that has been shown to function as part of the overall machinery for HR-based repair and genome stabilization [56]. In contrast, DSCC1 (also known as $\mathrm{hDCC} 1$ ) is known to be a component of the replication factor $\mathrm{C}$ (RFC) complex that contributes to DNA replication, and to have phenotypes related to DNA cohesion $[57,58]$; however, it has never been implicated in cisplatin resistance. Similarly, WDHD1 is a WD40domain rich protein that has been implicated in interaction with and regulation of the pre-replicative complex in human cells, induced during genotoxic stress, making 

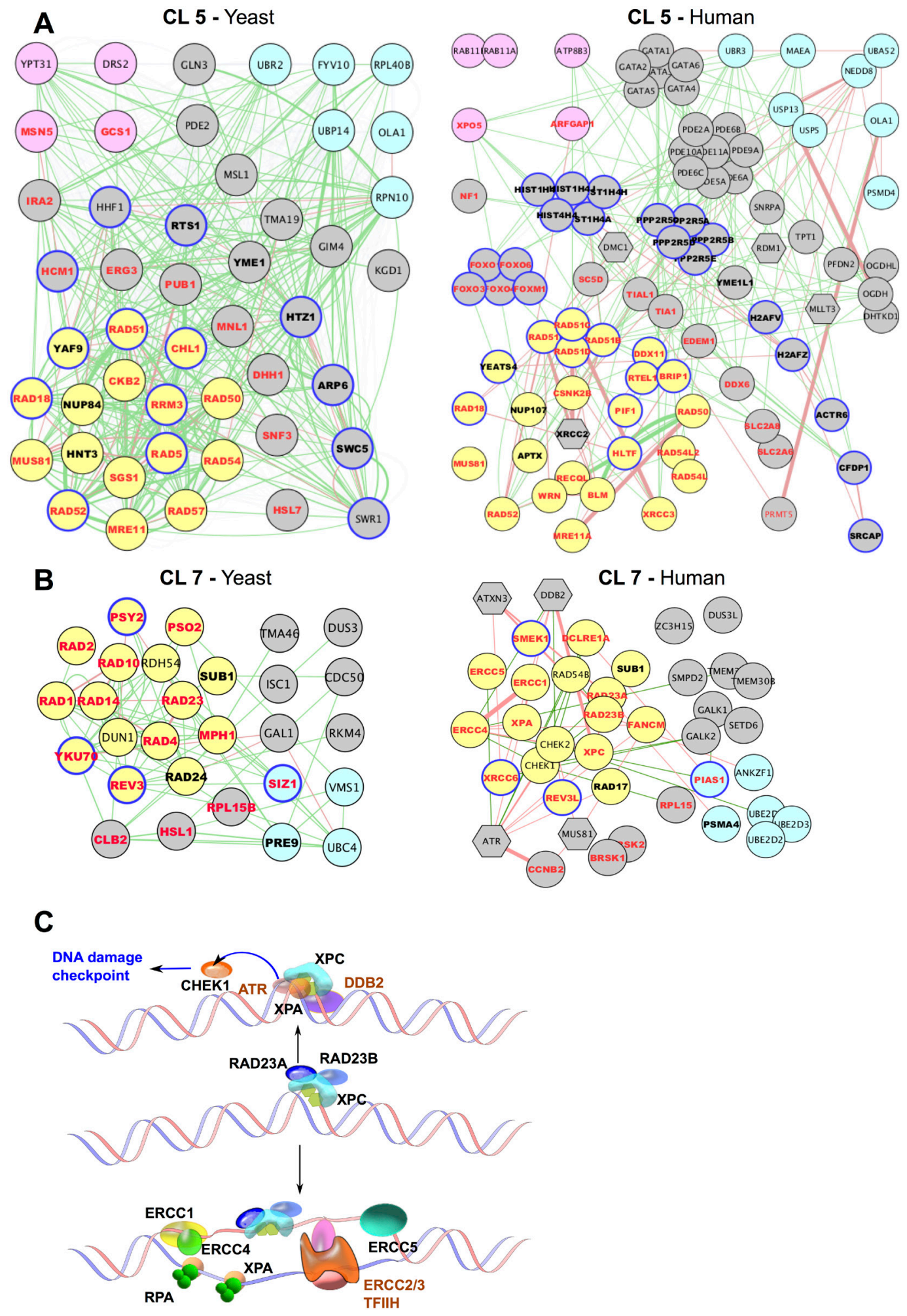

Figure 3: Evolutionary conservation of gene networks related to DDR. A, B. Gene networks for cluster 5 (A) and cluster 7 (B). For each cluster, networks of both yeast (left) and human (right) orthologous genes are shown. Gene Ontology (GO) functional annotations determined in yeast are indicated (on both yeast and human orthologs): DDR, yellow node fill; transport/secretion, pink node fill; proteosome/ubiquitination/degradation, light-blue node fill; chromosome/chromatin association, blue node outline. Bold font, cisplatin- and UV_rad sensitizing candidates; red font: cisplatin-sensitizing. Edges: physical interaction (red) or signaling interaction (green). Functionally connected, but not orthologous to yeast counterparts in the corresponding clusters, human genes are shown as hexagons. C. Schematic representation of defined components of the Nucleotide Excision Repair NER) pathway enriched in cluster 7 (black font) and associated signaling partners (brown). 
it a plausible regulator of sensitization to DNA damage $[59,60]$. WDHD1 has also never been shown to influence cisplatin resistance.

Together, this work emphasizes the growing realization that DDR-relevant functions can be disseminated across broad networks of genes that are not obviously related to the core DDR machinery. As genomic testing becomes standard in the clinic, a major challenge has been to use this information to develop prognostic markers, and identify actionable therapeutic targets, to improve clinical outcomes. Recent studies have catalogued mutations in defined DDR genes in cancer, correlating mutations or expression changes in these genes with genomic instability and gene expression changes that predict response to current therapies [61]. Collectively, this work has led to clinical gains, identifying proteins that can be therapeutically targeted alone or in synthetically lethal combinations with other drugs, or specific DNA lesions. The exceptional responses of patients with BRCA mutations to olaparib and other PARP1-targeting drugs provide a clear example of the utility of such an approach [62]. Such work also has potential importance in identifying patients who might respond to newer treatment options such as immunotherapies, given the appreciation of the importance of tumor-specific mutated proteins that arise from a high mutational burden in providing epitopes that can be recognized by the immune system $[63,64]$.

While much work has focused on study of genes most directly related to core machineries related to HR, MMR, NHEJ, and other specific DNA repair processes, a number of recent studies have illustrated functionally important control of activity of repair proteins by signaling systems previously thought to function independently. Additional control of the repair process may be mediated in part by epigenetic regulators or microRNAs (miRs) [65, 66]. For example, the recent recognition that androgen signaling regulates expression of a suite of DDR genes accentuates the importance of considering non-canonical candidates for control of therapy resistance [67]. The model provided by this study suggests an orthogonal approach to understand this type of biological network. However, these data also emphasize the challenges of developing reliable prognostic biomarkers, or identifying unique, targetable DDR genes to improve
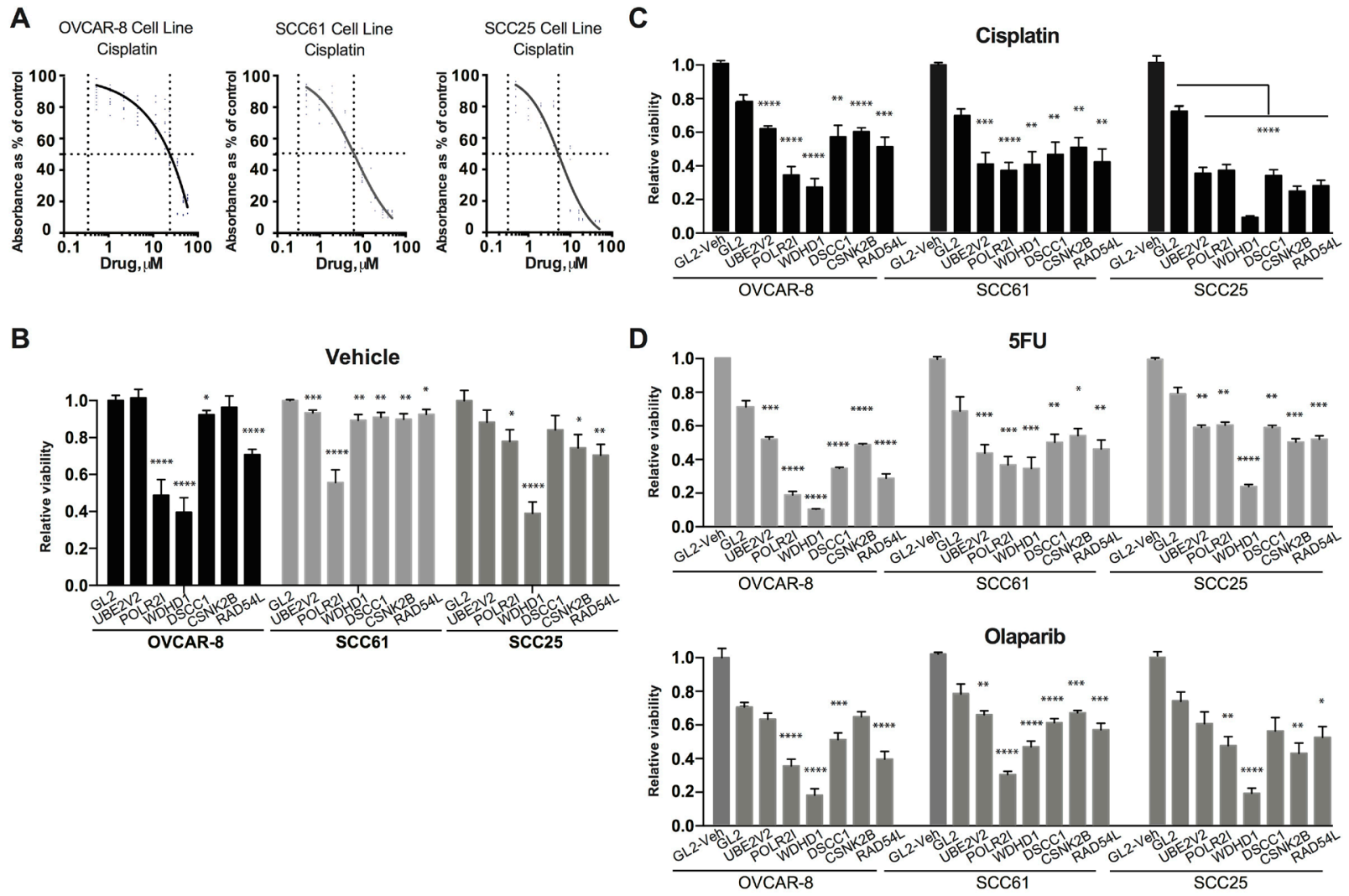

Figure 4: Evaluating candidate gene regulation of sensitivity to cisplatin treatment. A. IC50 determination for cisplatin for the OVCAR-8, SCC61, and SCC25 cell lines. B. Relative viability of OVCAR-8, SCC61, and SCC25 cell lines assessed by CellTiterBlue (CTB) following treatment with negative control siRNA (GL2) or siRNAs targeting the indicated genes. Data are normalized to CTB values for GL2. C. Relative viability of cells treated with the indicated siRNAs 72 hours after treatment with IC20-30 levels of cisplatin. GL2/ vehicle treated cells are included as reference. D. Data as for C., except following treatment of cells with 5-FU (top) or olaparib (bottom). $*, \mathrm{P}<0.05, * *, \mathrm{P}<0.01, * * *, \mathrm{P}<0.001, * * * *, \mathrm{P}<0.0001$ for all graphs. 

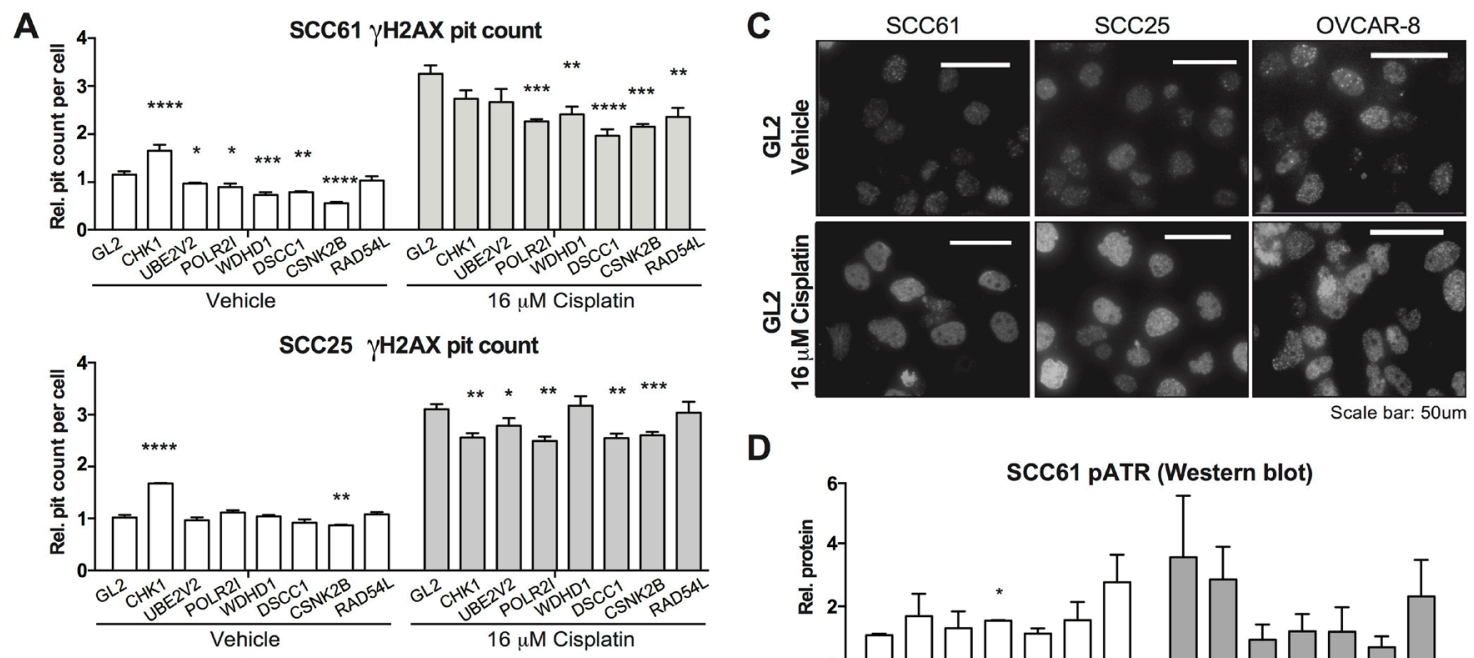

D
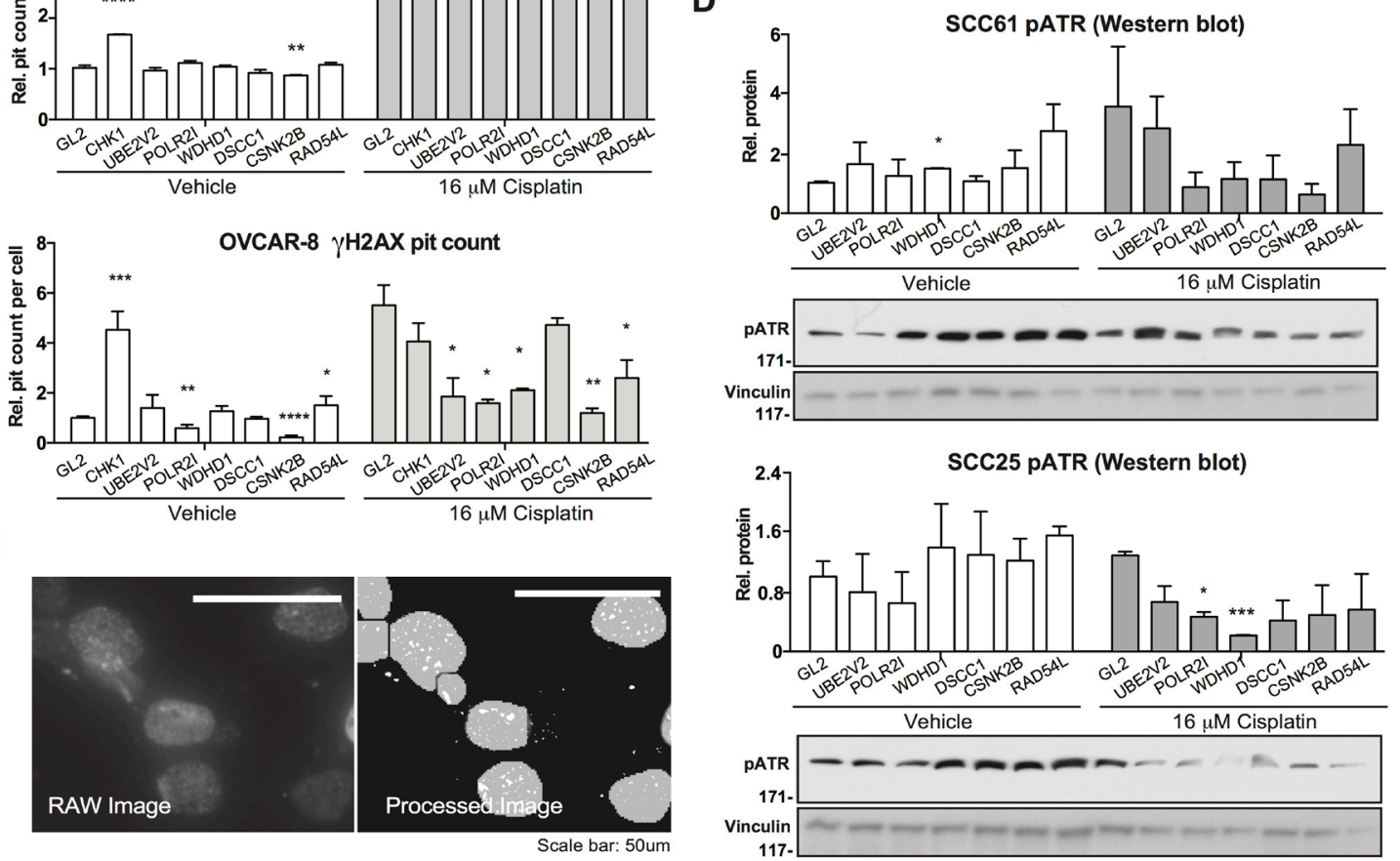

Figure 5: Evaluation of candidate gene regulator of DNA damage responses. A. Quantification of number of $\gamma \mathrm{H} 2 \mathrm{AX}$-positive foci per cell nucleus for cells transfected with negative control GL2 siRNA, or siRNA targeting indicated genes, 18 hours following treatment with vehicle (DMSO) or cisplatin as indicated. Data are normalized to values for GL2-transfected cells. B. $\gamma \mathrm{H} 2 \mathrm{AX}$ foci were quantified by automated scoring using MetaXpress software. Image shows representative raw and processed images used for quantitation. C. Representative images for vehicle-versus cisplatin-treated cells for the indicated cell lines, as quantified in A. D. Representative images and quantification for phosphorylated ATR. *, $\mathrm{P}<0.05$, **, $\mathrm{P}<0.01, * * *, \mathrm{P}<0.001$, ****, $\mathrm{P}<0.0001$ for all graphs.
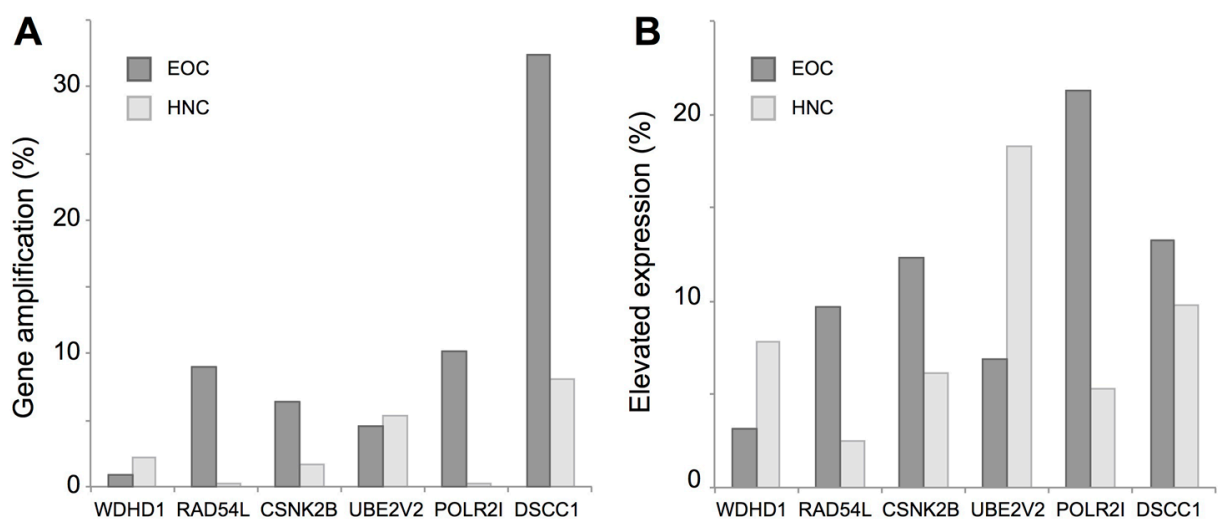

Figure 6: Copy number variation (CNV) and genes expression for cisplatin resistance genes based on TCGA profiling. A. Percent of tumors with elevated copy number of the indicated genes, based on analysis of 488 HPV-HNCs (light gray) and 540 EOCs (dark gray) in the TCGA data set. B. Percent HPV- HNC or EOC tumors with elevated expression (z score >2) in the TCGA dataset. 
cisplatin response, when large numbers of genes each make incremental contributions to treatment resistance phenotypes. It is likely that, as more chemogenomics, protein-protein and genetic studies become available (see [68]), a similar integrative approach will identify additional genes beyond the networks described here. Additionally, assessment of epigenetic changes, including DNA methylation [69] and gene silencing [70] for cisplatin resistance in the context of distinct tumor subtypes may yield different patterns of dependence, based on which genes are expressed in which tumor subclasses. For example, even among HNCs, the HPV-negative subtype analyzed here has features that distinguish it from HPVpositive disease $[71,72]$. Further work is clearly needed.

\section{MATERIALS AND METHODS}

Detailed methods for analysis of datasets, performance of siRNA analysis, and antibodies for Western blotting are found in Supplementary Materials Online Methods.

\section{Identification of genes and human orthologs relevant to radiation and/or cisplatin resistance in model organisms}

S. cerevisiae genes with loss-of-function phenotypes of reduced resistance to radiation or cisplatin were identified from the Saccharomyces Genome Database (SGD, accessed 02/02/2015) [21], and integrated with data manually curated from published screens. Genes relevant to radiation and/or cisplatin resistance in $D$. melanogaster and $C$. elegans were extracted from FlyBase [38], and WormBase [40], respectively. Human orthologs of genes defined through analysis of $S$. cerevisiae, D. melanogaster, and $C$. elegans were obtained through batch searches using Ensemble Biomart (http://useast.ensembl.org/biomart/ martview/) [73].

\section{Clustering, functional enrichment, and TCGA analysis}

Data corresponding to the chemogenomic analysis of a homozygous deletion mutant collection were retrieved from the supplementary materials of Hillenmeyer et al [37] and imported in Multiple experiment Viewer (MeV, [74]). Following the optimal gene function-predicting strategy identified in ref [37], we have employed unsupervised complete-linkage hierarchical cluster analysis [74], using uncentered Pearson correlation. Clusters containing more than 15 genes (arbitrary size selection), and containing three or more UV_rad or cisplatin resistance genes were identified, and the statistical significance of enrichment of these clusters for the UV_rad and/ or cisplatin sensitivity mutants was calculated using a hypergeometric distribution test. Functional enrichment of clusters was analyzed using DAVID $[75,76]$, normalized to results from the complete list of 4,769 genes for which homozygous $S$. cerevisiae single deletion strains are available. A threshold of 15 genes for minimal cluster size was selected to allow statistical significance in estimations of gene function enrichment. For TCGA analysis, the most recent datasets for ovarian serous cystadenocarcinoma and head and neck squamous cell carcinoma (as of August 25, 2016) were accessed and analyzed using tools available at cBioPortal for Cancer Genomics (http://www.cbioportal. org/, [52]).

\section{Cell culture}

SCC25 SCCHN cells were obtained from the American Type Culture Collection (ATCC). SCC61 SCCHN cells and the ovarian carcinoma cell line OVCAR8 were obtained from the FCCC Cell Culture Facility. Authentication of all cell lines by genotyping was performed by IDEXX BioResearch (Columbia, MO). SCC61 and SCC25 cell lines were cultured in DMEM-F12 media containing 10\% fetal bovine serum (FBS), L-glutamine (L-glu) and penicillin/streptomycin (pen/strep). OVCAR8 was cultured in RPMI-1640 media containing 10\% FBS, L-glu and pen/strep.

\section{siRNA drug sensitization and validation}

Human genes to be assessed for modulation of cisplatin sensitivity were depleted using siRNAs from Qiagen (Hilden, Germany) with positive and negative controls for transfection and normalization. After 24 hours recovery, cells were treated with cisplatin or vehicle for 72 hours, cell viability measured using a Cell Titer Blue assay (Promega, Madison, WI ), and sensitization index (SI) determined. For each gene of interest, siRNA sensitization assays were initially performed with 4 independent siRNAs; subsequently, the two best performing RNAs (Supplementary Table 8) were pooled and used for functional testing. For evaluation of depletion efficacy, at 48 hours after transfection, total RNA was extracted using the RNeasy Mini Kit (Qiagen, Hilden, Germany), reverse-transcribed using standard approaches and analyzed by Taqman chemistry using Assay-on-Demand (Supplementary Table 9). To explore specificity of genes for response to cisplatin, 24 hours post transfection with pooled siRNAs, cells were treated in parallel with selected concentrations of cisplatin, 5-fluorouracil (5-FU), paclitaxel, olaparib or vehicle. All drugs, except olaparib, were obtained in Fox Chase Cancer Center Pharmacy. Olaparib was purchased from LC Laboratories, Woburn, MA. After 72 hours, a CellTiterBlue assay was performed following the manufacturer's protocol, and the SI was determined for each drug as previously described [18]. 


\section{Automated immunofluorescence detection of $\gamma-\mathrm{H} 2 \mathrm{AX}$}

The quantitative assay of formation of foci containing phosphorylated histone $\mathrm{H} 2 \mathrm{AX}(\gamma-\mathrm{H} 2 \mathrm{AX})$ in SCC25, SCC61 and OVCAR8 cells was performed in cells transfected in triplicate in 96 well plates. CHEK1targeting siRNA was used as a positive control (M003255-04-0005 GE-Dharmacon, Lafayette, CO), and siGL2 as a normalization control. 24 hours post transfection cells were treated with 16 or $30 \mu \mathrm{M}$ cisplatin or with vehicle. After 18 hours, cells were washed with ice-cold PBS, fixed with 4\% PFA for $10 \mathrm{~min}$, washed again, permeabilized with $0.1 \%$ Triton-X100 and stained with anti- $\gamma \mathrm{H} 2 \mathrm{AX}$ primary antibodies $(1: 1000$, Mouse Monoclonal, Millipore Upstate, Billerica, MA) overnight at $+4 \mathrm{C}^{\circ}$, followed by staining with FITCtagged secondary antibodies (1:1000, goat anti-mouse IgG $(\mathrm{H}+\mathrm{L})$, Alexa Fluor ${ }^{\circledR} 488$ conjugate) for 1 hour at room temperature. 9 independent image fields from each individual well were acquired with an automated highthroughput screening-microscope (ImageXpress micro, Molecular Device Sunnyvale, CA), driven by MetaXpress software (Molecular Devices, Sunnyvale, CA). Images acquired from immunofluorescent samples were analyzed utilizing the Transfluor analysis module of MetaXpress allowing for quantitation of stained foci within nuclear segmentation. Automated cell counts and recognition were based on DAPI stained nuclear segmentation, with the $\gamma-\mathrm{H} 2 \mathrm{AX}$ staining score based on the quantitation of foci using the 'pit count per cell' parameter. Results from these analyses were displayed within Acuity (Molecular Devices, Sunnyvale CA) and Microsoft Excel.

\section{Western blot analysis}

SCC61 and SCC25 cells were transfected in 6 well plates, treated with $16 \mathrm{uM}$ Cisplatin for 18 hours and lysed in CelLytic MT Cell Lysis Reagent (Sigma-Aldrich, St. Louis, MO). Protein concentrations of the resulting lysates were measured using the Pierce BCA Protein Assay Kit (Thermo Scientific, Waltham, MA). Western Blotting was performed using standard procedures, and blots developed by chemiluminescence using Luminata Western HRP substrates (Classico, Crescendo and Forte, EMD Millipore). anti-phospho-ATR (Ser428) rabbit, polyclonal primary antibody (\#2853) was provided by, Cell Signaling, Danvers, MA. Quantification of signals on Western blots was done using the NIH ImageJ Imaging and Processing Analysis Software with signaling intensity normalized to loading control.

\section{ACKNOWLEDGMENTS}

The authors are grateful to Yan Zhou, for assistance with quality control assessments for siRNA analysis. The authors were supported by R21CA191425 from the NIH (to EAG), a Ruth L. Kirschstein NRSA F30 fellowship (F30 CA180607) from the NIH (to TNB), NCI Core Grant P30 CA006927 (to Fox Chase Cancer Center). Bioinformatics analysis was supported by the Russian Science Foundation (grant\#15-15-20032).

\section{CONFLICTS OF INTEREST}

The authors declare no conflicts of interest.

\section{REFERENCES}

1. Kelland L. The resurgence of platinum-based cancer chemotherapy. Nat Rev Cancer. 2007; 7: 573-84.

2. Dasari S, Tchounwou PB. Cisplatin in cancer therapy: molecular mechanisms of action. Eur J Pharmacol. 2014; 740: 364-78.

3. Teng PN, Bateman NW, Darcy KM, Hamilton CA, Maxwell GL, Bakkenist CJ, Conrads TP. Pharmacologic inhibition of ATR and ATM offers clinically important distinctions to enhancing platinum or radiation response in ovarian, endometrial, and cervical cancer cells. Gynecol Oncol. 2015; 136: 554-61.

4. Gadhikar MA, Sciuto MR, Alves MV, Pickering CR, Osman AA, Neskey DM, Zhao M, Fitzgerald AL, Myers JN, Frederick MJ. Chk1/2 inhibition overcomes the cisplatin resistance of head and neck cancer cells secondary to the loss of functional p53. Mol Cancer Ther. 2013; 12: 1860-73.

5. Cullen KJ, Yang Z, Schumaker L, Guo Z. Mitochondria as a critical target of the chemotheraputic agent cisplatin in head and neck cancer. J Bioenerg Biomembr. 2007; 39: 43-50.

6. Galluzzi L, Vitale I, Michels J, Brenner C, Szabadkai G, Harel-Bellan A, Castedo M, Kroemer G. Systems biology of cisplatin resistance: past, present and future. Cell Death Dis. 2014; 5: e1257.

7. O'Grady S, Finn SP, Cuffe S, Richard DJ, O'Byrne KJ, Barr MP. The role of DNA repair pathways in cisplatin resistant lung cancer. Cancer Treat Rev. 2014; 40: 1161-70.

8. Alkema NG, Wisman GB, van der Zee AG, van Vugt MA, de Jong S. Studying platinum sensitivity and resistance in highgrade serous ovarian cancer: Different models for different questions. Drug Resist Updat. 2016; 24: 55-69.

9. Mehra R, Zhu F, Yang DH, Cai KQ, Weaver J, Singh MK, Nikonova AS, Golemis EA, Flieder DB, Cooper HS, Lango M, Ridge JA, Burtness B. Quantification of excision repair cross-complementing group 1 and survival in p16-negative squamous cell head and neck cancers. Clin Cancer Res. 2013; 19: 6633-43.

10. Wu F, Lin X, Okuda T, Howell SB. DNA polymerase zeta regulates cisplatin cytotoxicity, mutagenicity, and the rate of development of cisplatin resistance. Cancer Res. 2004; 64: 8029-35.

11. Johnson N, Johnson SF, Yao W, Li YC, Choi YE, Bernhardy AJ, Wang Y, Capelletti M, Sarosiek KA, Moreau LA, 
Chowdhury D, Wickramanayake A, Harrell MI, et al. Stabilization of mutant BRCA1 protein confers PARP inhibitor and platinum resistance. Proc Natl Acad Sci U S A. 2013; 110: 17041-6.

12. Tan DS, Kaye SB. Chemotherapy for Patients with BRCA1 and BRCA2-Mutated Ovarian Cancer: Same or Different? Am Soc Clin Oncol Educ Book. 2015: 114-21.

13. Wang Y, Krais JJ, Bernhardy AJ, Nicolas E, Cai KQ, Harrell MI, Kim HH, George E, Swisher EM, Simpkins F, Johnson N. RING domain-deficient BRCA1 promotes PARP inhibitor and platinum resistance. J Clin Invest. 2016; 126: 3145-57.

14. Wood RD. (2014). http://sciencepark.mdanderson.org/labs/ wood/dna_repair_genes.html.

15. Wood RD, Mitchell M, Lindahl T. Human DNA repair genes, 2005. Mutat Res. 2005; 577: 275-83.

16. Shi X, Wang X, Shajahan A, Hilakivi-Clarke L, Clarke R, Xuan J. BMRF-MI: integrative identification of protein interaction network by modeling the gene dependency. BMC Genomics. 2015; 16 Suppl 7: S10.

17. Zhang YW, Nasto RE, Varghese R, Jablonski SA, Serebriiskii IG, Surana R, Calvert VS, Bebu I, Murray J, Jin L, Johnson M, Riggins R, Ressom H, et al. Acquisition of estrogen independence induces TOB1-related mechanisms supporting breast cancer cell proliferation. Oncogene. 2016; 35: 1643-56.

18. Astsaturov I, Ratushny V, Sukhanova A, Einarson MB, Bagnyukova T, Zhou Y, Devarajan K, Silverman JS, Tikhmyanova N, Skobeleva N, Pecherskaya A, Nasto RE, Sharma C, et al. Synthetic lethal screen of an EGFR-centered network to improve targeted therapies. Sci Signal. 2010; 3: ra67.

19. Rodriguez-Rodriguez L, Hirshfield KM, Rojas V, DiPaola RS, Gibbon D, Hellmann M, Isani S, Leiser A, Riedlinger GM, Wagreich A, Ali SM, Elvin JA, Miller VA, et al. Use of comprehensive genomic profiling to direct point-of-care management of patients with gynecologic cancers. Gynecol Oncol. 2016; 141: 2-9.

20. Plimack ER, Dunbrack RL, Brennan TA, Andrake MD, Zhou Y, Serebriiskii IG, Slifker M, Alpaugh K, Dulaimi E, Palma N, Hoffman-Censits J, Bilusic M, Wong YN, et al. Defects in DNA Repair Genes Predict Response to Neoadjuvant Cisplatin-based Chemotherapy in Muscle-invasive Bladder Cancer. Eur Urol. 2015; 68: 959-67.

21. Cherry JM, Hong EL, Amundsen C, Balakrishnan R, Binkley G, Chan ET, Christie KR, Costanzo MC, Dwight SS, Engel SR, Fisk DG, Hirschman JE, Hitz BC, et al. Saccharomyces Genome Database: the genomics resource of budding yeast. Nucleic Acids Res. 2012; 40: D700-5.

22. Begley TJ, Rosenbach AS, Ideker T, Samson LD. Damage recovery pathways in Saccharomyces cerevisiae revealed by genomic phenotyping and interactome mapping. Molecular cancer research. 2002; 1: 103-12.

23. Begley TJ, Rosenbach AS, Ideker T, Samson LD. Hot spots for modulating toxicity identified by genomic phenotyping and localization mapping. Molecular cell. 2004; 16: 117-25.
24. Bennett CB, Lewis LK, Karthikeyan G, Lobachev KS, Jin YH, Sterling JF, Snipe JR, Resnick MA. Genes required for ionizing radiation resistance in yeast. Nature genetics. 2001; 29: 426-34

25. Birrell GW, Giaever G, Chu AM, Davis RW, Brown JM. A genome-wide screen in Saccharomyces cerevisiae for genes affecting UV radiation sensitivity. Proc Natl Acad Sci U S A. 2001; 98: 12608-13.

26. Game JC, Birrell GW, Brown JA, Shibata T, Baccari C, Chu AM, Williamson MS, Brown JM. Use of a genome-wide approach to identify new genes that control resistance of Saccharomyces cerevisiae to ionizing radiation. Radiation research. 2003; 160: 14-24.

27. Giaever G, Flaherty P, Kumm J, Proctor M, Nislow C, Jaramillo DF, Chu AM, Jordan MI, Arkin AP, Davis RW. Chemogenomic profiling: identifying the functional interactions of small molecules in yeast. Proceedings of the National Academy of Sciences of the United States of America. 2004; 101: 793-8.

28. Hanway D, Chin JK, Xia G, Oshiro G, Winzeler EA, Romesberg FE. Previously uncharacterized genes in the UV- and MMS-induced DNA damage response in yeast. Proceedings of the National Academy of Sciences of the United States of America. 2002; 99: 10605-10.

29. Liao C, Hu B, Arno MJ, Panaretou B. Genomic screening in vivo reveals the role played by vacuolar $\mathrm{H}+$ ATPase and cytosolic acidification in sensitivity to DNA-damaging agents such as cisplatin. Molecular pharmacology. 2007; 71: 416-25.

30. Wu HI, Brown JA, Dorie MJ, Lazzeroni L, Brown JM. Genome-wide identification of genes conferring resistance to the anticancer agents cisplatin, oxaliplatin, and mitomycin C. Cancer research. 2004; 64: 3940-8.

31. Xia L, Jaafar L, Cashikar A, Flores-Rozas H. Identification of genes required for protection from doxorubicin by a genomewide screen in Saccharomyces cerevisiae. Cancer Res. 2007; 67: 11411-8.

32. Birrell GW, Brown JA, Wu HI, Giaever G, Chu AM, Davis RW, Brown JM. Transcriptional response of Saccharomyces cerevisiae to DNA-damaging agents does not identify the genes that protect against these agents. Proc Natl Acad Sci U S A. 2002; 99: 8778-83.

33. Lee W, St Onge RP, Proctor M, Flaherty P, Jordan MI, Arkin AP, Davis RW, Nislow C, Giaever G. Genome-wide requirements for resistance to functionally distinct DNAdamaging agents. PLoS Genet. 2005; 1: e24.

34. Cheung-Ong K, Song KT, Ma Z, Shabtai D, Lee AY, Gallo D, Heisler LE, Brown GW, Bierbach U, Giaever G, Nislow C. Comparative chemogenomics to examine the mechanism of action of dna-targeted platinum-acridine anticancer agents. ACS Chem Biol. 2012; 7: 1892-901.

35. Parsons AB, Lopez A, Givoni IE, Williams DE, Gray CA, Porter J, Chua G, Sopko R, Brost RL, Ho CH, Wang J, Ketela $\mathrm{T}$, Brenner C, et al. Exploring the mode-of-action of bioactive compounds by chemical-genetic profiling in yeast. Cell. 2006; 126: 611-25. 
36. Brown JA, Sherlock G, Myers CL, Burrows NM, Deng C, Wu HI, McCann KE, Troyanskaya OG, Brown JM. Global analysis of gene function in yeast by quantitative phenotypic profiling. Mol Syst Biol. 2006; 2: 20060001.

37. Hillenmeyer ME, Ericson E, Davis RW, Nislow C, Koller D, Giaever G. Systematic analysis of genome-wide fitness data in yeast reveals novel gene function and drug action. Genome biology. 2010; 11: R30.

38. Attrill H, Falls K, Goodman JL, Millburn GH, Antonazzo G, Rey AJ, Marygold SJ, FlyBase c. FlyBase: establishing a Gene Group resource for Drosophila melanogaster. Nucleic Acids Res. 2016; 44: D786-92.

39. Lyne R, Smith R, Rutherford K, Wakeling M, Varley A, Guillier F, Janssens H, Ji W, McLaren P, North P, Rana D, Riley T, Sullivan J, et al. FlyMine: an integrated database for Drosophila and Anopheles genomics. Genome Biol. 2007; 8: R129.

40. Howe KL, Bolt BJ, Cain S, Chan J, Chen WJ, Davis P, Done J, Down T, Gao S, Grove C, Harris TW, Kishore R, Lee R, et al. WormBase 2016: expanding to enable helminth genomic research. Nucleic Acids Res. 2016; 44: D774-80.

41. Nwizu T, Adelstein DJ. In squamous cell head and neck cancer: which platinum, how much and how often? Expert Rev Anticancer Ther. 2014; 14: 1033-9.

42. Longley DB, Harkin DP, Johnston PG. 5-fluorouracil: mechanisms of action and clinical strategies. Nat Rev Cancer. 2003; 3: 330-8.

43. Davar D, Beumer JH, Hamieh L, Tawbi H. Role of PARP inhibitors in cancer biology and therapy. Curr Med Chem. 2012; 19: 3907-21.

44. Jackson SP. Sensing and repairing DNA double-strand breaks. Carcinogenesis. 2002; 23: 687-96

45. Paull TT, Rogakou EP, Yamazaki V, Kirchgessner CU, Gellert M, Bonner WM. A critical role for histone H2AX in recruitment of repair factors to nuclear foci after DNA damage. Curr Biol. 2000; 10: 886-95.

46. Pabla N, Huang S, Mi QS, Daniel R, Dong Z. ATR-Chk2 signaling in p53 activation and DNA damage response during cisplatin-induced apoptosis. J Biol Chem. 2008; 283: 6572-83.

47. Turinetto V, Giachino C. Multiple facets of histone variant H2AX: a DNA double-strand-break marker with several biological functions. Nucleic Acids Res. 2015; 43: 2489-98.

48. Stransky N, Egloff AM, Tward AD, Kostic AD, Cibulskis K, Sivachenko A, Kryukov GV, Lawrence MS, Sougnez C, McKenna A, Shefler E, Ramos AH, Stojanov P, et al. The mutational landscape of head and neck squamous cell carcinoma. Science. 2011; 333: 1157-60.

49. Agrawal N, Frederick MJ, Pickering CR, Bettegowda C, Chang K, Li RJ, Fakhry C, Xie TX, Zhang J, Wang J, Zhang $\mathrm{N}$, El-Naggar AK, Jasser SA, et al. Exome sequencing of head and neck squamous cell carcinoma reveals inactivating mutations in NOTCH1. Science. 2011; 333: 1154-7.
50. Hoadley KA, Yau C, Wolf DM, Cherniack AD, Tamborero D, $\mathrm{Ng} \mathrm{S}$, Leiserson MD, Niu B, McLellan MD, Uzunangelov V, Zhang J, Kandoth C, Akbani R, et al. Multiplatform analysis of 12 cancer types reveals molecular classification within and across tissues of origin. Cell. 2014; 158: 929-44.

51. Cancer Genome Atlas Research N. Integrated genomic analyses of ovarian carcinoma. Nature. 2011; 474: 609-15.

52. Gao J, Aksoy BA, Dogrusoz U, Dresdner G, Gross B, Sumer SO, Sun Y, Jacobsen A, Sinha R, Larsson E, Cerami E, Sander C, Schultz N. Integrative analysis of complex cancer genomics and clinical profiles using the cBioPortal. Science signaling. 2013; 6: pl1.

53. Bologna S, Altmannova V, Valtorta E, Koenig C, Liberali P, Gentili C, Anrather D, Ammerer G, Pelkmans L, Krejci L, Ferrari S. Sumoylation regulates EXO1 stability and processing of DNA damage. Cell Cycle. 2015; 14: 2439-50.

54. Lu R, Niida H, Nakanishi M. Human SAD1 kinase is involved in UV-induced DNA damage checkpoint function. J Biol Chem. 2004; 279: 31164-70.

55. Santarpia L, Iwamoto T, Di Leo A, Hayashi N, Bottai G, Stampfer M, Andre F, Turner NC, Symmans WF, Hortobagyi GN, Pusztai L, Bianchini G. DNA repair gene patterns as prognostic and predictive factors in molecular breast cancer subtypes. Oncologist. 2013; 18: 1063-73.

56. Mason JM, Dusad K, Wright WD, Grubb J, Budke B, Heyer WD, Connell PP, Weichselbaum RR, Bishop DK. RAD54 family translocases counter genotoxic effects of RAD51 in human tumor cells. Nucleic Acids Res. 2015; 43: 3180-96.

57. Merkle CJ, Karnitz LM, Henry-Sanchez JT, Chen J. Cloning and characterization of hCTF18, hCTF8, and hDCC1. Human homologs of a Saccharomyces cerevisiae complex involved in sister chromatid cohesion establishment. J Biol Chem. 2003; 278: 30051-6.

58. Murakami T, Takano R, Takeo S, Taniguchi R, Ogawa K, Ohashi E, Tsurimoto T. Stable interaction between the human proliferating cell nuclear antigen loader complex Ctf18replication factor $\mathrm{C}(\mathrm{RFC})$ and DNA polymerase $\{$ epsilon $\}$ is mediated by the cohesion-specific subunits, $\mathrm{Ctf18}$, Dcc1, and Ctf8. J Biol Chem. 2010; 285: 34608-15.

59. Li Y, Xiao H, de Renty C, Jaramillo-Lambert A, Han Z, DePamphilis ML, Brown KJ, Zhu W. The involvement of acidic nucleoplasmic DNA-binding protein (And-1) in the regulation of prereplicative complex (pre-RC) assembly in human cells. J Biol Chem. 2012; 287: 42469-79.

60. Bermudez VP, Farina A, Tappin I, Hurwitz J. Influence of the human cohesion establishment factor Ctf4/AND-1 on DNA replication. J Biol Chem. 2010; 285: 9493-505.

61. Chae YK, Anker JF, Carneiro BA, Chandra S, Kaplan J, Kalyan A, Santa-Maria CA, Platanias LC, Giles FJ. Genomic landscape of DNA repair genes in cancer. Oncotarget. 2016; 7:23312-21. doi: 10.18632/oncotarget.8196.

62. Lord CJ, Tutt AN, Ashworth A. Synthetic lethality and cancer therapy: lessons learned from the development of PARP inhibitors. Annu Rev Med. 2015; 66: 455-70. 
63. Castle JC, Kreiter S, Diekmann J, Lower M, van de Roemer N, de Graaf J, Selmi A, Diken M, Boegel S, Paret C, Koslowski M, Kuhn AN, Britten CM, et al. Exploiting the mutanome for tumor vaccination. Cancer Res. 2012; 72: 1081-91

64. Brown SD, Warren RL, Gibb EA, Martin SD, Spinelli JJ, Nelson BH, Holt RA. Neo-antigens predicted by tumor genome meta-analysis correlate with increased patient survival. Genome Res. 2014; 24: 743-50.

65. Liu H, Gao F, Dahlstrom KR, Li G, Sturgis EM, Zevallos JP, Wei Q, Liu Z. A variant at a potentially functional microRNAbinding site in BRIP1 was associated with risk of squamous cell carcinoma of the head and neck. Tumour Biol. 2016; 37: 8057-66.

66. Zhao L, Tang M, Hu Z, Yan B, Pi W, Li Z, Zhang J, Zhang L, Jiang W, Li G, Qiu Y, Hu F, Liu F, et al. miR-504 mediated down-regulation of nuclear respiratory factor 1 leads to radioresistance in nasopharyngeal carcinoma. Oncotarget. 2015; 6: 15995-6018. doi: 10.18632/oncotarget.4138.

67. Polkinghorn WR, Parker JS, Lee MX, Kass EM, Spratt DE, Iaquinta PJ, Arora VK, Yen WF, Cai L, Zheng D, Carver BS, Chen Y, Watson PA, et al. Androgen receptor signaling regulates DNA repair in prostate cancers. Cancer Discov. 2013; 3: 1245-53.

68. Venancio TM, Bellieny-Rabelo D, Aravind L. Evolutionary and Biochemical Aspects of Chemical Stress Resistance in Saccharomyces cerevisiae. Front Genet. 2012; 3: 47.

69. Koutsimpelas D, Pongsapich W, Heinrich U, Mann S, Mann WJ, Brieger J. Promoter methylation of MGMT, MLH1 and RASSF1A tumor suppressor genes in head and neck squamous cell carcinoma: pharmacological genome demethylation reduces proliferation of head and neck squamous carcinoma cells. Oncol Rep. 2012; 27: 1135-41.

70. Kailasam A, Mittal SK, Agrawal DK. Epigenetics in the Pathogenesis of Esophageal Adenocarcinoma. Clin Transl Sci. 2015; 8: 394-402.

71. Rampias T, Sasaki C, Psyrri A. Molecular mechanisms of HPV induced carcinogenesis in head and neck. Oral Oncol. 2014; 50: 356-63.

72. Seiwert TY, Zuo Z, Keck MK, Khattri A, Pedamallu CS, Stricker T, Brown C, Pugh TJ, Stojanov P, Cho J, Lawrence MS, Getz G, Bragelmann J, et al. Integrative and comparative genomic analysis of HPV-positive and HPV-negative head and neck squamous cell carcinomas. Clin Cancer Res. 2015; 21: $632-41$

73. Yates A, Akanni W, Amode MR, Barrell D, Billis K, Carvalho-Silva D, Cummins C, Clapham P, Fitzgerald S, Gil L, Giron CG, Gordon L, Hourlier T, et al. Ensembl 2016. Nucleic Acids Res. 2016; 44: D710-6.

74. Saeed AI, Sharov V, White J, Li J, Liang W, Bhagabati N, Braisted J, Klapa M, Currier T, Thiagarajan M, Sturn A, Snuffin M, Rezantsev A, et al. TM4: a free, open-source system for microarray data management and analysis. Biotechniques. 2003; 34: 374-8.

75. Huang da W, Sherman BT, Zheng X, Yang J, Imamichi T, Stephens R, Lempicki RA. Extracting biological meaning from large gene lists with DAVID. Current protocols in bioinformatics / editoral board, Andreas D Baxevanis [et al]. 2009; Chapter 13: Unit 131.

76. Huang da W, Sherman BT, Lempicki RA. Systematic and integrative analysis of large gene lists using DAVID bioinformatics resources. Nature protocols. 2009; 4: 44-57. 